\title{
APRESENTAÇÃO DO DOSSIÊ: VIAGEM E LITERATURA
}

\author{
Denn man reist ja nicht, um anzukommen, \\ sondern um zu reisen. ${ }^{1}$ \\ Johann Wolfgang von Goethe, \\ Diálogo com Caroline von Herder, 1788
}

A seção de Literatura do presente número de Letrônica, a revista digital do Programa de Pós-Graduação em Letras da Pontifícia Universidade Católica do Rio Grande do Sul (PUCRS), propõe o tema "Viagem e Literatura”. Poder-se-ia considerar uma surpresa para os editores o número relativamente grande de artigos enviados para apreciação, uma vez que o tema é raro nas propostas dos nossos periódicos, no elenco das disciplinas ofertadas nos cursos de pós-graduação e nos encontros da área. Mas o desejo de estudar, analisar e comentar textos sobre essa relação só demonstra o que o leitor assíduo constata com certa facilidade: a viagem constitui um dos temas mais antigos e frequentes das várias literaturas, e se mantém porque apresenta a capacidade de expressar não apenas relatos sobre o deslocamento físico, mas engloba toda uma representação simbólica do movimento mental e intelectual e da própria vida.

Observem-se, por exemplo, algumas das mais famosas epopeias, da Antiguidade ao início da era moderna - a Odisseia, Beowulf, Jerusalém libertada, Os Lusíadas. Em todas elas a saga do homem, a conquista, o ato fundador das nações está plasmado em atos que exigiram o deslocamento no espaço e a coragem da flexibilidade do pensamento. Livros inteiros da Bíblia, que influenciou escritores em todas as culturas, são igualmente relatos de viagens. Lembremo-nos do Livro do Êxodo, cujo título veio a tornar-se

\footnotetext{
${ }^{1}$ Pois não viajamos para chegar ao destino, e sim para viajar.
} 
símbolo de movimentos memoráveis até nossos dias. Tais movimentos implicam abandono do anteriormente próprio e busca do inicialmente estrangeiro, que pode vir a ser apropriado e incorporado no futuro.

Dos inúmeros exemplos que poderíamos citar, limitamo-nos a apenas mais alguns: As viagens de Marco Polo, Robinson Crusoé, de Daniel Defoe, As viagens de Gulliver, de Jonathan Swift, Viagens na minha terra, de Almeida Garrett, Anton Reiser, de Karl Philipp Moritz, As peregrinações de Wilhelm Meister, de Goethe, Tristes Trópicos, de Claude Lévi-Strauss, As vozes de Marrakech, de Elias Canetti. Em alguns desses, temos pura e utópica fantasia, em outros, uma viagem real recebe tratamento literário, o que a afasta da assim-chamada "literatura dos viajantes" - cientistas, aventureiros, curiosos, que receberam imensa atenção por ocasião de efemérides como os quinhentos anos do descobrimento da América ou do Brasil - e a inclui na literatura propriamente dita ou em um terreno misto e nebuloso, em que realidade e fantasia são indistinguíveis. Isso para não falarmos naquelas obras, cada vez mais numerosas, como O livro do desassossego, de Bernardo Soares, em que se conta uma viagem nunca realizada, e que se dá apenas no mundo interior, expresso pelas palavras. A viagem também não se prende a formas literárias, podendo ser encontrada tanto na poesia épica quanto na prosa narrativa e no poema breve.

Em um simpósio sobre "Narrativas de Viagem: Modernidade e o Espaço Imaginário", organizado pelo Departamento de Inglês da Universidade de Zurique em dezembro de 2013, foram propostos os seguintes painéis: espaços liminares; visão e lugar na escrita de viagem do século XIX; teorias do lugar e do espaço; modalidades espaciais de ver; ilhas literárias; mapeamento cinematográfico do "self"; limiares e regiões costeiras; utopia/distopia e memória; cruzamento de fronteiras; o mar como espaço de troca; mapeamento do espaço; narrativa de viagem e re-visão/revisitação; o imaginário do Atlântico; imaginando o Havaí; fluidez, dissolução de fronteiras; exílio e escrita da vida; poética da ilha; espaços transnacionais; "selves" migrantes; desenraizamento (cf. http://www.es.uzh.ch/teaching/PhD/phdlit/TravellingNarratives .html). Essa diversidade dá ao leitor uma noção das possibilidades de associação de ideias com o tema, bem como de sua abrangência, que se estende tanto sobre espaços discutidos em diferentes contextos da área como também sobre outros que não são 
comumente associados à literatura. Este é, naturalmente, apenas um exemplo das diversas abordagens possíveis do tema.

Os articulistas que contribuíram com o presente número de Letrônica também optaram pela diversidade. É o que se pode notar em uma breve vista d'olhos sobre o sumário.

"A questão do estrangeiro em Paul Ricoeur" e "Teoria da leitura como contato cultural: deslocamentos, viagens e alteridade no ato da leitura de ficções" não tratam do tema da viagem por meio da análise de obras narrativas, mas de questões teóricas relacionadas à viagem. A "teoria da leitura" mencionada pelo segundo artigo foi criada pela californiana Gabriele Schwab na década de 1990.

Em seguida, podemos agrupar uma série de artigos que tratam de obras estrangeiras que apresentam como tema diferentes facetas da viagem. Em "Caminhando pela vida, o desafio de Maksim Gorki", são discutidas as obras autobiográficas desse autor russo. Sabidamente, Infância, Ganhando meu pão e Minhas universidades estão entre suas obras mais apreciadas e populares. Todas elas implicam a busca e o deslocamento.

“O rito de passagem da viagem em 0 amor em tempo de cólera, de Gabriel García Márquez" aborda essa importante associação, cujas raízes já podemos encontrar no Parsifal, de Wolfram von Eschenbach: a viagem é um passo essencial para desprenderse, não só da infância e dos pais, mas do passado em geral, em busca da vida adulta e da maturidade.

"A travessia do rio mudando identidades culturais, causando des-locamentos Um estudo sobre a obra de Caryl Phillips" explora a obra desse escritor centroamericano nascido em 1958, de origem africana. Nele se encontra a descrição da diáspora africana nas Américas em livros como, entre outros, Crossing the river.

Os diários de viagem, segundo o autor do artigo seguinte, oferecem importante via de acesso à experiência do viajante e suas reações à nova sociedade em que busca inserir-se, e também constituem uma via de compreensão do período da cultura da nova sociedade. É o que se pode observar no interessantíssimo Brazilian journal (1987), de P. K. Page, que viveu como estrangeira no Rio de Janeiro da primeira metade do século XX.

Os dois artigos seguintes apresentam contribuições ao tema da viagem por meio da análise de obras da literatura portuguesa. 0 primeiro, "Viagens de Caim: Uma viagem 
cronotópica do romance de José Saramago", realiza uma cronotopoanálise do romance Caim (2009), de José Saramago, obra que se constitui enquanto releitura de episódios bíblicos do Velho Testamento. 0 protagonista realiza viagens por meio de transgressões espaço-temporais. 0 conceito de "cronotopo" é de Bakhtin e refere-se à indissociabilidade das categorias espaço e tempo.

O segundo, “A viagem e o indivíduo exilado: uma leitura aproximativa entre Luís de Camões e António Lobo Antunes", apresenta uma leitura do romance Sôbolos rios que vão, de Lobo Antunes, baseado no famoso poema homônimo de Camões. Em ambos os textos temos a presença de exilados. Saúde e doença, tempo anterior e tempo presente, infância e maturidade são aspectos observados comparativamente pelo autor do artigo em ambas as obras.

Tal como no artigo anterior, os dois artigos seguintes apresentam a forma poética como objeto de análise, desta vez em poemas brasileiros. 0 primeiro deles é "A viagem na lírica final de Jorge de Lima"; o segundo, "A encenação representada no (dis)curso de uma retirada: Morte e vida Severina". É sabido que o poema de João Cabral de Melo Neto narra a viagem a pé de um grupo de flagelados da seca, do interior do Nordeste para a grande cidade, Recife. 0 artigo se detém na escritura poética e na encenação. Como já dissemos, o tema da viagem não se prende a formas literárias, fazendo-se presente tanto na prosa quanto na poesia, dividida em cenas, à moda teatral, como a de João Cabral, ou mais breve, como a de Jorge de Lima.

Assim como esses, todos os demais artigos tomam como base textos da literatura brasileira, estendendo-se do Modernismo aos nossos dias. "O turista aprendiz no Nordeste e as rachaduras do sistema patriarcal: estudo das crônicas 'O grande cearense' e 'Tempos de dantes', de Mário de Andrade" apossa-se desses textos pouco conhecidos de um dos criadores do Modernismo, sabidamente um grande viajante, que optou por viajar somente pelo Brasil.

"Viagens imaginárias em Primeiras estórias, de Guimarães Rosa" analisa o tema da viagem nos contos "Pirlimpsiquice", "Partida do audaz navegante" e "Nenhum, nenhuma". 0 universo infantil é desvendado a partir de estudos sobre o autor. "Olhando para trás e em frente: perspectivas de viagens em 'Olhando para trás e em frente', de Tutameia terceiras estórias, de João Guimarães Rosa” pretende identificar os motivos que impulsionam os personagens para viajar, bem como observar o traçado desse 
itinerário. Segundo o autor, a viagem torna-se diversa em sua configuração, à medida que não são apenas viagens por estradas reais, por terra e por rio, por meio de montaria ou de barco. 0 tema da viagem em Tutameia configura-se também pela metáfora do olhar para frente e para trás, o que se reverte na ação do próprio leitor na travessia de ir e vir.

Os três últimos artigos representam a literatura contemporânea. "Perder-se na viagem, na estrada, na história: o estrangeiro em Bem longe de Marienbad, de Caio Fernando Abreu", desenvolve o conceito de estrangeiro na novela mencionada de Abreu com base na obra Estrangeiros para nós mesmos, de Julia Kristeva. A ideia singular na obra de Abreu é que, para os personagens errantes, a estrada pode se constituir em um novo lar.

"Viagem, desterro e narratividade: considerações sobre Ana em Veneza, de João Silvério Trevisan" tece considerações sobre o romance do título a partir da imagem do desterro, palavra que podemos associar com êxodo, exílio, diáspora, todas já mencionadas em sua relação com o deslocamento e a viagem. 0 autor vale-se de seu conhecimento da obra de Thomas Mann para tratar dos temas associados da desilusão e da morte.

Por fim, "A viagem existencial em Antonio, de Beatriz Bracher", segundo a autora, faz uma exposição do tema da viagem que se desdobra espacial e existencialmente. 0 personagem Teo, narrado pelas vozes de três diferentes narradores, é o viajante que, em sua jornada, sofre transmutação física e psicológica, seguindo um destino trágico que o leva à loucura. Mas não são os acontecimentos que mais importam nessa narrativa, e sim o sentido da viagem.

Esperamos que também os artigos aqui brevemente anunciados se transformem em um prazer equivalente àquele com que Goethe nos acena na epígrafe desta apresentação: que não seja a conclusão da leitura que nos anime, mas o prazer de desfrutá-la.

Os organizadores,

Prof. Dr. Pedro Theobald (Professor do Pós-Graduação em Letras da PUCRS)

Doutoranda Luara Pinto Minuzzi (Doutoranda e editora-júnior - PUCRS) 